\title{
Glosario usual de Cundinamarca (GUC): Una experiencia lexicográfica*
}

\author{
José Aldemar Álvarez Valencia** \\ Angélica Patricia Hoyos Guzmán***
}

\section{Resumen}

Las dinámicas actuales de las sociedades modernas y postmodernas hacen que haya una constante creación y flujo de unidades léxicas cuyo origen se hace cada vez más difícil de identificar. Este documento se propone reportar una experiencia investigativa en el área de la lexicografía que se llevó a cabo en algunos pueblos de la región de Cundinamarca. A través de grabaciones de audio de conversaciones informales, entrevistas y cuestionarios se buscó elaborar un glosario de naturaleza dialectal. Las conclusiones indican que debido a la movilidad de los habitantes de la ciudad de Bogotá hacia los pueblos de Cundinamarca y viceversa, es difuso determinar un vocabulario específico.

\section{Palabras claves}

Lexicografía, glosario, uso, léxico dialectal.

* Resultado de investigación realizada en el Seminario Andrés Bello, Instituto Caro y cuervo.

** Licenciado en Español e Inglés, Magíster en Lingüística Aplicada y candidato a Magíster del Instituto Caro y Cuervo. Docente e investigador de la Universidad de la Salle. Correo electrónico:josea_edu@yahoo.com.

*** Licenciada en Lenguas Modernas, candidato a Magíster Instituto Caro y Cuervo. Investigadora Fundación Palabrería, Proyecto Cultural. Correo electrónico: hoyosguzman@gmail.com. 


\section{Abstract}

The current dynamics of modern and postmodern societies generate a constant creation and flow of lexical units whose origin is every time more difficult to identify. This paper aims at reporting a research experience in the field of lexicography that was carried out in the region of Cundinamarca. Through audio-recording of informal oral interactions, interviews and questionnaires, it was intended to elaborate a glossary of dialectal nature. The conclusions show that due to the mobility of the people of Bogotá towards the different towns of Cundinamarca and vice versa, it is still problematical to determine a specific vocabulary.

\section{Key words}

Lexicography, glossary, use, dialectal lexicon.

\section{Prefacio}

Un vallenato recién llegado a Bogotá inaugura su primer viaje en transmilenio. Más asustado que asombrado se sube en la estación de la avenida Jiménez y al entrar al automotor se acomoda en medio del tumulto de gente que lo rodea. En la siguiente estación se sube un grupo de jóvenes y el hombre se dice así mismo: -"icaramba pero qué bollitos! Se queda perplejo escuchando hablar a las muchachas entre ellas: "-iMarica! No supe que decirle uo'n"- el vallenato no entiende nada y se pregunta: "- ¿uo'n? ¿Quéfue lo que dijo?" - No comprende la manera de tratarse entre ellas, pues en la Costa Atlántica "marica" normalmente se les dice a los hombres que gustan de otros hombres, es decir a los homosexuales.

La anterior, constituye una escena típica de la urbe bogotana en donde se entrecruzan no sólo una gran cantidad de personas sino también sus culturas, sus idiosincrasias, sus dialectos. Por esta razón podría parecer difícil, en principio, delimitar un glosario dialectal a partir del habla en la capital 
colombiana. Sin embargo, aludiendo a la tesis de Ángel Rosenblat (Cf. 1971) sobre la unidad del español sustentada en la diversidad de modalidades lingüísticas regionales, este glosario surge como un intento de registrar los rasgos diferenciales del léxico registrados en la comunidad lingüística cundinamarquesa, puesto que consideramos que, en estos días, a pesar de la proliferación de la mezcla de dialectos en la ciudad, es necesario ahondar en las particularidades del habla en el departamento desde esta investigación lexicográfica.

\section{Descripción de la experiencia}

Para la realización del glosario no sólo se tuvo en cuenta a los hablantes de Santa Fe de Bogotá sino también a los hablantes de algunas poblaciones de Cundinamarca tales como: Villeta, Tocaima, La Vega y Guaduas. Ello constituye una constante indagación sobre las peculiaridades en el habla del departamento a la que se pretende responder en cierto grado con este glosario, a manera de ejercicio lexicográfico. Así, el visitante, nacional o extranjero, que llega a la región -ya sea a la capital o a alguno de las poblaciones vecinas- atraído por la historia, por la gastronomía, por los paisajes o por la gran urbe, se encontrará con una variedad lingüística en el sector rural, que bajo nuestra óptica, no dista mucho del habla citadina.

A lo recientemente enunciado atribuimos el hecho de que la cercanía geográfica de los municipios a la ciudad permite una constante movilidad social de personas que por razones académicas, económicas o familiares visitan a la ciudad capital con mucha frecuencia, asimilando también características del habla. Así se justifica la semejanza entre los rasgos lingüísticos del habla bogotana y aquellos que se encontraron en algunas poblaciones del departamento.

Decimos algunos puesto que somos conscientes de la variedad recreada en la anécdota que relatamos al comenzar este escrito, y es bien conocido desde nuestra investigación los problemas que esta cercanía geográfica trae consigo al momento de delimitar nuestro glosario. Es así como, al iniciar la investigación nos encontramos con que se localizaron semejanzas en el 
léxico del habla en la ciudad y las poblaciones visitadas. Revisando el Atlas Lingüístico y Etnográfico de Colombia7 (Cf.Fernández Sevilla, 1974) nos percatamos de que la cercanía geográfica permitía que también se compartieran elementos léxicos con el departamento de Boyacá. Incluso al preguntarle a algunos informantes oriundos de Cundinamarca sobre el origen de sus familias ellos nos daban respuestas que alternaban con topónimos relativos a Boyacá o a Cundinamarca.

La limitante que surgió entonces fue ¿Cómo delimitar un rasgo diferencial del léxico únicamente registrado en Cundinamarca? Nos propusimos solventar de algún modo esta problemática partiendo del análisis del registro en el habla de personas nacidas en Bogotá y de las personas oriundas de los pueblos que se visitaron, en procura de una homogeneidad en el uso del léxico. De este modo se abordó la génesis del léxico a partir de las características y matices de sentido en el seno de la sociedad, la industria y la técnica evidenciadas en el registro de los hablantes. Para tal fin es necesario también utilizar como soporte el registro etnográfico llevado a cabo durante la visita realizada a los pueblos entre los meses de marzo y octubre, como también los registros tomados en la ciudad durante los meses de mayo a octubre de 2006.

De acuerdo con lo anterior, enmarcamos el glosario dentro de la tipología de los vocabularios dialectales, en el sentido diferencial del habla peninsular en relación con el habla americana, según un criterio de uso evidenciado en la región. Por tal razón se hizo necesaria la comparación del corpus constituyente del vocabulario con el registro de los lemas que aparecen en el Diccionario Académico y en el Diccionario de Colombianismos. Así, el criterio de selección

Nos hace hincapié en la necesidad corroborar los usos diatópico a partir de la revisión de los atlas dialectales; por tal motivo accedemos a esta revisión como una de las fuentes primarias para la elaboración del glosario que nos permita determinar una extensión geográfica. Sin embargo es necesario tener en cuenta la desactualización a la que puede enfrentarse el léxico registrado en esta obra, por lo que se hace necesario estableces un criterio de actualidad para la selección de entradas respaldado por el uso actual de los lemas. 
de entradas correspondió a aquellos lemas que no aparecieran en las obras anteriormente citadas o aquellos que tuvieran un sentido diferente que no hubiera sido registrado en dichas obras.

Dicho criterio de selección está respaldado por un arduo proceso de investigación. Éste consistió primeramente en visitar los pueblos antes enunciados y llevar a cabo grabaciones de interacciones casuales, entrevistas abiertas y observaciones directas. En la ciudad, las anotaciones sobre el léxico se hicieron a partir de observaciones y fueron corroborados los usos con las encuestas realizadas en los pueblos. Dichas observaciones se registraron en su mayoría en sitios públicos.

El proceso arrojó un corpus constituido por 120 palabras -adicionando a ellas las registradas en el ALEC (Cf. Flórez, 1981-1983) de las cuales tuvo que corroborarse el uso para incluir únicamente aquellas que todavía son vigentes en Cundinamarca y delimitarlas del léxico de Boyacá. Los lemas fueron registrados en fichas de formato DIN A 6 según el proceso sugerido por Günter Haensch (Cf. 1982) y confrontados con los diccionarios que se mencionaron anteriormente, y con el uso efectivo a partir de las encuestas (ver anexo 1), ello ayudó en gran medida a depurar la muestra que aquí se presenta, la cual constituye un número de 30 entradas.

Como se ha dicho en las líneas anteriores, el soporte principal para la selección de esas entradas lo ha constituido el estudio etnográfico realizado en el departamento. Por tal motivo, este glosario se inscribe bajo las características de una obra lexicográfica de corte social que concibe el inventario léxico como constructo social (Cf. Lara, 1990) evidenciado por los hablantes de la comunidad cundinamarquesa. En esa medida su funcionalidad se dirige precisamente a servir a los usuarios interesados en conocer y comprender mejor los rasgos del habla popular en el departamento.

De este modo, el glosario puede ser útil tanto para una persona con conocimientos en lingüística interesado en los problemas dialectales y lexicográficos en esta región, como para un turista de procedencia nacional que se vea enfrentado a las peripecias lingüísticas que se sufren al ser pertenecientes a 
una comunidad distinta de hablantes, a pesar de compartir la misma lengua histórica. También puede ser útil para el turista extranjero que visita Colombia con la ilusión de conocer y entender la cultura y, qué mejor muestra de nuestro país que nuestra diversidad dialectal.

La realización de este glosario fue posible gracias a la colaboración de los informantes en Cundinamarca y Bogotá. Los realizadores agradecen a los habitantes de Villeta, Guaduas, La Vega y Nocaima su participación en las entrevistas y el acogimiento en sus municipios. Así mismo, agradecemos el aporte que, desde la cátedra de Lexicografía en el Seminario Andrés Bello, nos brindaron nuestros compañeros y docentes de la de la Maestría en Lingüística de 2006, quienes siempre estuvieron prestos a asistir de manera solidaria y desinteresada la realización de este trabajo.

\section{Características del GUC}

\subsection{Criterios de selección de las entradas}

\subsubsection{Criterios externos}

\section{Finalidad}

El Glosario Usual de Cundinamarca que se presenta tiene como objeto describir las realidades léxico-semánticas que han dejado de ser registradas en el Diccionario de la Real Academia de la lengua Española o en el Diccionario de Colombianismos, bien por necesidad de un estudio más detallado del tesoro léxico característico del departamento o bien por la evolución de la lengua y el surgimiento de nuevas palabras que aparecen después de la impresión de los respectivos diccionarios. En este sentido, el GUC pretende dar cuenta del estado de la lengua española y su variante léxico diatópica en Cundinamarca, en el momento en que sale a la luz. 


\section{Grupo de usuarios}

Este glosario está dirigido a los siguientes usuarios:

- A los profesores y estudiantes de la lengua española interesados en conocer las características específicas del idiolecto cundinamarqués, a nivel léxico, y en profundizar en la conciencia lingüística sobre el conocimiento de la variedad compartida en la comunidad de habla. Puede servir así como herramienta lúdico-pedagógica que motive las clases de español y literatura en cualquier nivel educativo.

- Al público versado en los problemas de la lengua española y el lenguaje en su uso, aquí cabe mencionar a los lingüistas, filólogos, dialectólogos y lexicógrafos que vean en el glosario algún interés particular que enriquezca determinada investigación en este nivel de lengua del español.

- Al público general con pocos o escasos conocimientos en lingüística que vean en el glosario una herramienta útil para comprender el habla de este departamento, teniendo en cuenta la migración continua de personas provenientes de otras partes de Colombia, e inclusive de otras partes del mundo al departamento como centro de interés tanto turístico como laboral.

Según las características que definen los usuarios potenciales de este glosario, se procura que la redacción y las definiciones halladas en el inventario léxico sean claras, y estén dotadas de la información necesaria para satisfacer las necesidades del grupo al que se dirige la obra y para cumplir con la finalidad propuesta, sin dejar a un lado la técnica lexicográfica que sustenta la labor realizada. De este modo al sistematizar la elaboración y redacción del glosario se tienen en cuenta los postulados de Günter Haensch.

\section{Extensión}

Ésta se define a partir del trabajo previo de selección de los lemas cuyo resultado constituye un inventario léxico compuesto por 30 palabras. El proceso de selección que se llevó a cabo permitió delimitar el corpus según 
se describe en el siguiente apartado.

\subsubsection{Criterios internos}

Al tener la característica de ser un glosario Dialectal, se ha tomado como punto de inicio en esta labor lexicográfica lo recomendado por Fernández Sevilla quien alude a la necesidad de corroborar la extensión geográfica de un vocablo en los atlas lingüísticos. En este sentido, se revisó el Atlas Lingüístico Etnográfico de Colombia con el fin de tener una idea previa del registro diatópico para Cundinamarca. Lo anterior constituyó una primera dificultad en la labor realizada, pues se evidenció la similitud léxica compartida por el territorio correspondiente a la meseta cundi-boyacense en la mayoría de los mapas que contiene el ALEC, razón por la cual hubo que seleccionar algunos municipios como: La Vega, Tocaima, Villeta y Guaduas, y delimitar el léxico específico para ellos. De todo lo anterior surgió un corpus de 22 lexemas que fueron corroborados mediante entrevistas en los lugares señalados, de los cuales la mayoría se confirmo su desuso por el desconocimiento del lexema por parte de los hablantes. En este primer acercamiento sólo se evidenció como conocida y usada una palabra que aparecerá registrada en el inventario de este glosario como arcaísmo.

El siguiente paso fue recoger un corpus de fuentes secundarias de tipo oral y escrito tales como infogramas, prensa, radio y entrevistas abiertas, así como grabaciones encubiertas de interacciones con el fin de obtener elementos para el corpus definitivo, a partir del registro efectivo de la riqueza léxica de los hablantes de los municipios visitados y en algunos casos se tuvo en cuenta el registro de hablantes oriundos de los pueblos y habitantes de la ciudad. Como resultado se obtuvo un número mayor de lemas los cuales se sometieron al cotejo entre el DRAE y el Diccionario de Colombianismos de Günter Haensch y Reinhol Werner, con el fin de descartar del inventario aquellos lemas que aparecían ya en dichas obras lexicográficas y corroborar nuevas acepciones de un lema allí encontrado. El resultado del cotejo sirvió de base para la elaboración de una encuesta con el fin de comprobar el uso y conocimiento de los vocablos por los hablantes de los pueblos y en algunos casos por los hablantes de la ciudad oriundos de los pueblos. En los casos en 
que un vocablo se tomó del habla de la ciudad de Bogotá, éste se corroboró en los pueblos, lo cual perseguía el objetivo de obtener un inventario más o menos homogéneo y común en los hablantes del departamento.

De acuerdo con lo anterior, se tuvo como criterio diferencial, con respecto al español estándar, que las unidades léxicas simples y complejas fueran utilizadas en todos los lugares visitados y que fuera corroborado su uso como variante diatópica dentro del léxico de la comunidad de los pueblos en Cundinamarca. En esta medida, se eliminaron del glosario algunos vocablos registrados por los hablantes con un uso más generalizado y compartido por otros hablantes de otras regiones del país; aunque se mantuvieron otros que presentaron una alta frecuencia de uso en la región y que no aparecían en el DRAE y el Diccionario de Colombianismos. En este sentido predominó la frecuencia de uso para designar un vocablo como dialectal, dado que se hacia necesario registrarlo como parte del inventario léxico; una revisión más detallada de vocablos como estar jodido puede delimitar los usos y las variantes de dicha unidad en Colombia.

En resumen los criterios que avalan la selección del corpus son:

- Sincrónico: en la medida en que se atiende al estado de la variante léxico diatópico actual. Aún así no se dejan de lado aquellos vocablos dialectales que arrojó el ALEC y que hoy podrían considerarse como arcaísmos; por esto en la selección se optó por incluir aquellos que son usados con alta frecuencia por la población encuestada. Se toman como arcaísmos en la medida en que la obra de Flórez registra el estado del léxico entre 1970 y 1980 y han pasado ya más de 20 años desde su publicación, en los cuales la evolución de la lengua ha permitido el detrimento de algunos lexemas. Los que aún subsisten se registran acá para dar cuenta de su uso durante la época en que se recoge un corpus para la elaboración de esta obra.

- Descriptivo: en la relación que guarda el uso de los vocablos seleccionados con la descripción de las realidades lingüísticas que designan los contextos 
compartidos por la comunidad lingüística cundinamarquesa.

- Diferencial: desde el criterio geolectal se pretende que el glosario sea diferencial del español estándar, en varios niveles: diferentes acepciones de un vocablo, diferente ortografía o pronunciación y expresiones fraseológicas propias de la región y evidenciadas por el uso. Desde el criterio lexicográfico se apunta a que sea diferencial de las obras enunciadas anteriormente DRAE y Diccionario de Colombianismos.

- De uso: en la medida en que se atiende a la frecuencia de uso de cada vocablo para estimar la selección del mismo dentro del inventario.

- Selectivo: en la inclusión o exclusión de vocablos de acuerdo con las pautas anteriores. Es de aclarar que no se tiene en cuenta la información etimológica en la medida en que no se pretende realizar un diccionario histórico, y es muy difícil establecer la etimología de la creatividad léxica de algunas palabras, aun así se utiliza el paréntesis etimológico con el ánimo de ampliar la información y origen gramatical del uso de algunos vocablos. Para asegurar que los lemas fueran de uso en la lengua española, se eliminaron del corpus constituyente del inventario las palabras correspondientes a extranjerismos y tecnicismos con el ánimo de que el material aquí presentado cumpla con la característica de ser exclusivamente selectivo de las unidades léxicas dialectales en su uso.

- Semasiológico: al presentar las entradas en orden alfabético desde el significante hacia el significado.

\subsection{El material léxico}

El GUC contempla dentro de su inventario unidades léxicas tanto simples como pluriverbales. Las primeras constituyen sustantivos, adjetivos y verbos teniendo en cuenta los afijos modificadores tales como aumentativos. En cuanto a las fraseologías se incluyen como locuciones, modismos o fórmulas de carácter pragmático. En este sentido María Isabel González (2002-2003, 29 ss) asevera que la competencia léxica de los hablantes no sólo está constituida 
por palabras combinadas de acuerdo con las reglas gramaticales, sino que existe otro conjunto de voces complejas que se forman por la articulación de fragmentos del discurso que se unen para producir una forma fija. De esta forma se producen las fraseologías, que en general son producto del uso en el habla de la lengua.

En cuanto a los ejemplos que se incluyen en las entradas, algunos hacen parte del uso registrado en las grabaciones de entrevistas e interacciones y material escrito, mientras que otros son adaptaciones de los mismos para brindar mayor claridad. En este sentido nos dice Manuel Alvar (1982, 151 ss), que los ejemplos funcionan en el diccionario como elementos del metalenguaje, son glosas que informan sobre las connotaciones de las palabras, y para este caso nos acercarán más a las connotaciones que se le da a los lemas tanto simples como pluriverbales.

Es necesario examinar en detalle los aspectos que permiten configurar el material léxico del glosario, en la medida en que Haensch (Cf. 1982) dice que un diccionario se estructura según tres aspectos a considerar: A. Macroestructura y ordenación de los materiales en conjunto (para el caso semasiológico y alfabético). B. Las partes de un diccionario: parte introductoria, cuerpo del diccionario. C. Microestructura: estructuración de los artículos (lematización). Focalizando sobre este último aspecto se puede describir la microestructura del GUC de acuerdo con las siguientes instrucciones de uso.

\subsection{Advertencias para el uso de este glosario}

La microestructura de acuerdo con Garriga Escribano (1999) informa acerca de la estructura u ordenación de los elementos que componen un artículo lexicográfico. El artículo está compuesto a su vez por un lema o entrada, una definición. En este sentido es pertinente empezar por aclarar qué es una definición y una acepción. De acuerdo con Fernández-Sevilla, la definición lexicográfica es una "secuencia lingüística mas o menos amplia que aporta información acerca del signo que sirve de entrada" (Fernández Sevilla, 1974, 68) Por otro lado, Medina acentúa que una definición es la "Expresión por la que se describe un sentido" (Medina, 2003, 131) y con respecto a la acepción 
adiciona que es el "Sentido consolidado por el uso y aceptado por una comunidad de hablantes" (Medina, 2003, 131) Bajo estos preceptos se intenta abordar la definición en el GUC.

Ahora bien, tratando de acordar un orden para los artículos lexicográficos se tiene en cuenta que estos elementos (Cf. Alvar Ezguerra, 1993) poseen una estructura general que se puede observar a través del diccionario. Martínez de Sousa (1995) afirma que los diccionarios de lengua generalmente disponen el artículo lexicográfico de manera que la entrada está primero, luego la descripción lingüística, la definición y la fraseología. Es de aclarar que, en cuanto a la fraseología, en algunos casos se prefiere tomar las unidades pluriverbales independientemente como las expresiones idiomáticas que constituyen formas fijas.

En cuanto a las locuciones aparecen como lemas dependientes de aquel que tiene la mayor carga semántica dentro de la frase y se tiene en cuenta que éstas pueden alterar su forma sin perder el sentido, a diferencia de los modismos o expresiones idiomáticas que se consideran en el GUC como formas fijas. De este modo, se tiene en cuenta el valor referencial y la irradiación semántica que adquieren las locuciones en el uso efectivo y su realidad inmediata, lo que en los diccionarios generales, si bien se incluyen algunos de estos elementos, no se detalla con rigurosidad el uso diferencial que pueden tener las locuciones o modismos como pertenecientes a una determinada comunidad lingüística, con variaciones en el repertorio lingüístico que utilizan los hablantes, en contraste con la lengua estándar.

Es de aclarar también el tipo de definición que se tendrá en cuenta en este glosario. Ahumada Lara en 1989 habla de cinco tipos de definición lexicográfica, a saber, la enciclopédica, la lexicográfica y dentro de esta última, la definición híbrida, la sinonímica, la perifrástica y la morfosemántica. Para el caso de los lemas contenidos en el GUC, se puede hablar del tipo de definición perifrástica, ya que ésta permite "reproducir mediante perífrasis el resultado del análisis sémico a que se ha sometido una unidad de la lengua" (Ahumada Lara, 1989, 141). En el caso de algunos vocablos se ha optado por recurrir al tipo de definición enciclopédica tratando de reproducir las reali- 
dades semánticas que hacen parte de la región en sus aspectos diatópicos, diafásicos y diastráticos. Se decidió introducir un apartado de las instrucciones de uso en el glosario, para la óptima utilización por parte del usuario. En este sentido, se tomó como modelo para la exposición del manejo del mismo, los preliminares del DRAE con el fin de facilitar la consulta, como se presenta a continuación.

\subsubsection{Manejo del diccionario}

\section{Orden alfabético}

Las entradas están ordenadas alfabéticamente según lo dispuesto por el orden latino internacional por acuerdo del X congreso de la Asociación de Academias de la Lengua Española (Madrid, 1994). La grafía " $\mathrm{CH}^{\text {" es tomada }}$ como dígrafo y las entradas que comienzan por dicha letra se sitúan en el lugar correspondiente a la grafía " $C$ ". En cuanto a la grafía " $L L$ " no aparecen entradas registradas para ésta pero se recomienda en una futura ampliación o reelaboración del GUC incluirlas dentro del inventario de la grafía " $L$ ", de acuerdo con las tendencias actuales de la técnica lexicográfica. El inventario contiene entradas que se disponen en aparición así: A, B, C, D, E, G, J, N P, R, $S, V, Y, Z$.

\section{Variantes}

Con relación a los vocablos que pueden aparecer ortográficamente diferentes, se opta por escribir las dos variantes en el glosario, escribiendo la variante separada por coma al lado del lema principal; esto con el fin de evitar las remisiones para hacer más ágil la consulta del diccionario.

\section{Inclusión de las formas complejas dentro del glosario}

El glosario recoge tanto formas simples como formas complejas o fraseologías, buscando registrar la irradiación semántica de dichos elementos en el habla oral y escrita. De esta manera se presentan según las siguientes pautas: 
- Se toman como modismos o expresiones idiomáticas aquellas formas complejas que constituyen una estructura fija para el significado, cuyo sentido depende de toda la estructura y al alterar algunos de sus elementos pierden la lectura semántica de la expresión en su uso. De este modo, aparecen como entidades autónomas e independientes dentro del inventario léxico y se ordenan de acuerdo con la letra que inicie la estructura en el alfabeto.

- Se toman como locuciones aquellas formas que permiten alterar sus componentes gramaticales sin perder el sentido de las mismas. Éstas aparecen inventariadas de acuerdo con la palabra que tenga mayor carga semántica en la frase $y$, según este mismo criterio, se procura escribir después de la entrada el tipo de categoría gramatical a la cual corresponde. La mayor carga semántica se presenta dentro de la frase en una palabra que es la que le da el sentido completo al uso de la misma. Luego de la palabra enunciada en negrilla aparecerá un paréntesis que pretende aclarar la aparición de la expresión pluriverbal en el uso. Así aparecerá por ejemplo la palabra garra y seguidamente el paréntesis que deja ver la expresión completa (darse $\sim$ ), es de aclarar que la virgulilla remplazará el lema sólo en el caso de que el mismo se quiera enunciar en una fraseología.

\subsubsection{Estructura de los artículos del glosario}

La estructura general de los artículos contenidos en el glosario se describe a continuación:

- Con el ánimo de establecer la diferencialidad del glosario, a partir de lo que se registra en el DRAE y en el Diccionario de Colombianismos, se opta por marcar aquellos lemas que aparecen en dichas obras así:

- Un asterisco $(*)$ : representa que los lemas aparecen en el DRAE y se incluyen en el GUC por variación ortográfica, morfológica, o por distinta acepción. Por ejemplo por variación ortográfica el lema salpullido. 
- Dos asteriscos $(* *)$ : representan que el lema aparece en el Diccionario de Colombianismos y guardan alguna relación con lo que se incluye en el GUC por variación en la acepción, o en la morfología como en el caso del uso del lema chisgononón en su forma aumentativa.

Hay que mencionar que en algunos casos las marcas de referencialidad del DRAE y del Diccionario de Colombianismos aparecerán dentro del paréntesis etimológico porque no se registran igual en estas obras sino que tienen una relación de origen gramatical con los lemas que se definen en el GUC.

- Primero aparece el lema en negrita con letra minúscula, luego aparece la marca gramatical, indicando la categoría del ítem léxico.

- Aparece la variante ortográfica del lema separada de coma si es requerido.

- En cuanto a los sustantivos se indican con la abreviatura m. y f. según el genero del vocablo.

- La variante morfológica de género gramatical aparece al final del lema enunciado, en negrilla y se separa mediante un guión, según el caso.

- La naturaleza de los verbos aparece marcada por medio de las abreviaturas intr. o tr.

- También se incluye la marca para el adjetivo, según se requiera.

- Aparecen también las marcas diastráticas como en el caso de coloquial o vulgar, y en el caso de las locuciones se registran de acuerdo con su categoría gramatical.

- Aparecen las marcas diafásicas según el valor afectivo de la lengua irónico o despectivo.

- En algunos casos, antecede a la marca gramatical el paréntesis etimológico que indica el origen gramatical del vocablo o aclaraciones sobre 
la forma en que se presenta la construcción lingüística de una locución para presentarla cuando se define el vocablo según la carga semántica representativa del mismo.

- Aparece la virgulilla ( ) cuando ésta remplaza al lema que hace parte de una fraseología, en el caso de los ejemplos se escribe el lema igual a como aparece en la entrada.

- Las acepciones aparecen separadas mediante la doble plecal seguida de numeración arábiga, y se utiliza la doble pleca gruesa o en negrilla para separar las fraseologías.

- Los ejemplos aparecen señalados por la abreviatura de la palabra ejemplo: Ejm.

- Se describe el origen de los ejemplos mediante las abreviaturas:

M: ejemplo modificado

T: ejemplo fuente escrita.

O: ejemplo fuente oral.

I: ejemplo inventado a partir de las fuentes.

- El contorno, o explicaciones del uso del vocablo aparecen encerrados entre corchetes por ejemplo: [persona].

- La información complementaria o enciclopédica aparece separada mediante un calderón ๆ.

- El tipo de definición como ya se enunció es perifrástica y no se considerarán los sinónimos o antónimos con el fin de no generar confusiones en el matiz semántico que tienen los vocablos.

- Aparecen al final de la entrada las locuciones y variaciones de las mismas en cuanto a su categoría gramatical. 
3.3.3 Abreviaturas y signos empleados en el diccionario

* $\quad$ Aparece en el DRAE

** Aparece en el Diccionario de Colombianismos

Adj:: $\quad$ adjetivo

arc.: $\quad$ arcaísmo

aum.: $\quad$ aumentativo

coloq.: coloquial

desp.: despectivo.

exp. idiom.: expresión idiomática

interj. U.: $\quad$ interjección usada

intr.: $\quad$ verbo intransitivo

irón.: Irónico, irónicamente

loc. adj.: locución adjetival

loc. verb.: locución verbal

loc. prep. : locución preposicional

m. pl.: masculino plural

m. y f.: masculino y femenino

tr.: $\quad$ verbo transitivo

U.t.c.prnl.: úsese también como pronominal

U.t.c. dim.

vulg.: vulgar

M: $\quad$ ejemplo modificado

T: $\quad$ ejemplo fuente escrita

$\mathrm{O}: \quad$ ejemplo fuente oral

I: ejemplo inventado a partir de las fuentes. 


\section{Glosario usual de Cundinamarca (GUC)}

A

*abeja adj. coloq. [persona] con habilidad para engañar o evitar un engaño. |2. El que es perspicaz o astuto. Ejm. M. O. jEs que es muy abeja, siempre encuentra la forma de ganar! |3. irón. Falto de inteligencia. Ejm. M. O. No sea tan abeja, piense antes de actuar.

**aguarapado adj. [persona] que actúa sin timidez o cautela. Ejm. M. O. y aguarapado se fue y le echó los perros a la muchacha. |2. Embriagado con guarapo. Ejm. I. Ya estaba todo aguarapado y no me podía ni levantar.

banquitas $\mathrm{f}$. juego deportivo similar al fútbol que se juega con cinco jugadores en cada equipo y que se caracteriza por utilizar arcos con postes y largueros de un metro de largo. Ejm. M. O. Perdimos el último partido de banquitas dos a cero.

bitute m. coloq. conjunto de productos que necesita beber y comer [alguien] para subsistir. Ejm. M. O. Conseguir el bitute diario.

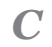

cacha (Forma corta de cachaza*) f. comportamiento indolente o descarado [de una persona]. Ejm. M. O. Tener la cacha de llegar ebrio al trabajo.

chichi (forma corta de chichipato*) adj. desp. [persona] que escatima en gastar su dinero. Ejm. O. No sea tan chichi, cómprele algo a su mamá. ¡2. [objeto u ocasión] de mala calidad. Ejm. O. La película estuvo muy chichi me dormí en la mitad.

chisgononón $\mathrm{m}$. (Del aum. de chisga**) producto que se comercia a un precio menor del acostumbrado. Ejm. T. Chisgononón. Aproveche Renault en perfectas condiciones. 
chimbear intr. vulg. causar molestia o irritación [a alguien]. Ejm. I. No me venga a chimbear que estoy ocupado.

chimbero-a m. y f. coloq. [Persona] que tiene éxito, consigue o gana algo de manera inesperada o como producto del azar. Ejm. M. Mi hermano es muy chimbero para las rifas.

chimbilo m. objeto para protegerse contra la lluvia o el sol que está compuesto por una pieza alargada de metal o de madera, que tiene en su extremo una estructura plegable hecha con varillas delgadas organizadas en forma radial, a las cuales se adhiere una tela. Ejm. I. No olvide traer el chimbilo que va a llover.

*cobre (pelar o mostrar el $\sim$ ) loc. verb. hacer visible [alguien] los defectos o malas intenciones que no eran antes evidentes. Ejm. M.O. Se creía que era buena persona, pero pelo el cobre.

cuajar v. tr. coloq. realizarse el proceso de la fecundación. |2. quedar [una mujer] en embarazo. Ejm. M. O. Parece que les cuajó porque por ahí los vi con bebe.

cusque, cuzque $\mathrm{m}$. arc. accesorio que se utiliza en la cabeza que tiene una parte hueca o la copa y una segmento más ancho o ala que lo rodea en la parte baja. Ejm. M. O. Iba de cusque y ruana.

\section{D}

dar v. tr. entregar un producto o posesión a cambio de dinero. Ejm. M. O. Le doy a mil pesos la libra de plátanos. I Se usa con para indicar descuento en el precio de un producto.

\section{$E$}

estar ( en la mala) coloq. Loc. verb. atravesar por un momento o periodo de mala suerte. Ejm. M. O. Además de los conflictos familiares, tengo otros inconvenientes en el trabajo, creo que estoy en la mala. 
* gallo m. coloq. hecho a circunstancia que dificulta la normalidad en el funcionamiento de un objeto o desarrollo de una situación. Ejm. M. O. Los carros siempre tienen un gallo cuando no es el motor, es el radiador.!!Qué $\sim$ ! Interj. U. para denotar angustia frente a una situación difícil.

* garra (darse ) coloq. Loc. verb. excederse [una persona] en alguna de sus actuaciones. ¡2. Presentar un objeto u situación rasgos exagerados en su constitución o apariencia. Ejm. M. O. Los accidentes de carro a veces suceden cuando uno se da garra con el trago. U.t.c.prnl.

\section{$J$}

jodido-a adj. (Del participio de joder) dicho de una persona que a traviesa por una mala situación [económica o sentimental]. Ejm. I. Andar sin plata es muy jodido. 'estar de. loc. prep. Dicho de alguna dolencia física o problema en la salud. Ejm. I. El jugo del almuerzo no me hizo bien, estoy jodido del estomago.

\section{$N$}

*nada (vuelto-a ) coloq. Loc. adj. [persona u objeto] que se encuentra en mal estado o no tiene una función útil. Ejm. M. O. Un computador vuelto nada. ' Tener vuelto $\sim$ el. o estar vuelto $\sim$ de Loc. verb. Sentir alguna afección física. Ejm. M. O. Tengo vuelto nada el estomago. ; Andar o estar vuelto Loc. adj. Atravesar por un periodo anímico difícil. Ejm. $O$. No dormí y estoy vuelto nada.

*paila adj. coloq. que presenta indisposición o molestia de salud. Ejm. M. O. hoy estoy paila, me duele todo el cuerpo. |2. que atraviesa por un momento o circunstancia negativa. Ejm. M. O. Que cosa tan paila, nada me sale bien. |2. Interj. U. para denotar un resultado negativo. Ejm. M. O. ¡Paila! Me fue mal en el examen.

*para ( que afine) Exp. idiom. aprender y escarmentar como producto de 
una experiencia que causó daño, o perjuicio. Ejm. M. O. Siempre llegaba tarde al trabajo y lo echaron, eso le sirve pa' que afine I Suele usarse para indicar desaprobación del comportamiento de una persona.

**ipichirilo! interj. Grito usado en el juego del mismo nombre el cual consiste en golpear al compañero del lado si se ve un carro pequeño @ Generalmente usado por los jóvenes.

pichón adj. [persona] que practica el sexo de manera frecuente. Ejm. I. Se ufana de ser pichón pero nunca se le ve con mujeres. |2. m. tipo de comida que resulta de cocer la sangre de la vaca o del toro. Ejm. I. El pichón del toro le da a uno energías.

planera f. acción violenta que consiste en golpear de manera repetida con la parte plana del machete [a una persona]. Ejm. O. Toca darle una planera a la gente $p a^{\prime}$ que le paguen a uno.

resobado adj. [producto de panadería] que está hecho a base de mantequilla. Ejm. T. Sí hay pan resobado. ๆ comida típica de la Vega conocida también en otros pueblos de Cundinamarca.

\section{$\boldsymbol{S}$}

saraito adj. [estado del clima] que no es caluroso ni frío. Ejm. O. El día está como saraito.

*salir ( de los chiros) Loc. verb. experimentar un repentino y fuerte sentimiento de rabia. Ejm. M. O. Lo que me dijo me hizo salir de los chiros. U.t.c.prnl.

*salpullido, zalpullido m. brote proveniente de una alergia o picadura de insectos. Ejm. I. El médico me recetó una crema para el salpullido que me salió en la pierna. 
vago-ga adj. [persona] que es muy habilidoso para ejecutar una tarea. Ejm. O. Qué man tan vago hizo tres goles.

\section{$Y$}

yaya f. desp. persona hábil para engañar o hacer travesuras. Ejm. M. O. Ese chino es una yaya completa, no le gana nadie pa' joder. U. t. c. dim. yayita con mayor carga despectiva.

\section{Conclusiones}

Al valorar el trabajo llevado a cabo se puede concluir que el glosario constituye una pequeña muestra, muy limitado en su cobertura por lo cual se hace necesario hacer investigaciones de mayor amplitud a nivel geográfico dentro del departamento y contrastar los resultados que aquí se presentan con estudios sobre frecuencias de uso de los vocablos en otras regiones del país. Además de lo anterior, se hace necesario ahondar en el léxico de la lengua culta, en las investigaciones de corte lexicográfico que tengan en cuenta el nivel diafásico dialectal; debido a que en este trabajo sólo se tomaron elementos léxicos de la lengua popular en su uso.

En cuanto a la dificultad de determinar el léxico específico de la región hay que tener en cuenta que muchos términos de Cundinamarca se encuentran en otras regiones de Colombia, esto obedece a la diversidad cultural de Bogotá y la masiva movilidad social de sus habitantes hacia pueblos de la región cundinamarquesa con propósitos laborales o de esparcimiento. Esto se explica por qué en los hablantes del departamento se encuentra léxico proveniente de otras regiones de Colombia, lo que dificulta la labor de identificar el léxico particular de la región.

En este trabajo se optó, como ejercicio lexicográfico, por tomar el criterio de uso para establecer la inclusión del léxico dialectal. Sin embargo, se pueden dilucidar otras alternativas para profundizar en la determinación de un corpus específico de Cundinamarca teniendo en cuenta los puntos 
geográficos de la región, que se pueden abordar desde el norte, sur, este y occidente, ya que para el GUC sólo se tuvo en cuenta la cercanía geográfica de algunos municipios. Una limitante ante esta alternativa, para determinar un inventario estrictamente dialectal, la constituye el hecho de que existen límites geográficos difusos entre Cundinamarca y las regiones colindantes.

Otra alternativa para abordar la investigación sobre el léxico de Cundinamarca es la de excluir la recolección del corpus en la ciudad de Bogotá. En el GUC se integró el léxico de los hablantes de esta ciudad contrastando los rasgos léxicos de los municipios. De lo anterior se pudo notar el léxico común y excluir el diferencial pero resulta más difícil determinar un léxico particular en la ciudad en la medida en que es el foco más amplio de confluencia de personas de otras del país. 


\section{Anexo: Modelo de encuesta (fragmento)}

\section{LÉXICO USUAL DE CUNDINAMARCA}

Fecha: día mes año

Informante No

Edad: Lugar de origen: Lugar de residencia:

Tiempo de residencia: Ocupación:

A continuación encontrará una serie de palabras o expresiones. Marque con una $x$ (equis) si las conoce y con que frecuencia las utiliza. En caso de que use la palabra o expresión, escriba al frente cual es el significado.

\begin{tabular}{|l|l|l|l|l|l|}
\hline \multirow{2}{*}{ PALABRA O EXPRESIÓN } & \multicolumn{2}{|c|}{ LA USA Y LA CONOCE } & \multirow{2}{*}{ NO LA CONOCE } & \multirow{2}{*}{ SIGNIFICADO } \\
\hline & & & & & \\
\hline 1. Abecuentermente & PoCO & Nadud & & \\
\hline 2. Aguarapado & & & & & \\
\hline 3. Alevinos & & & & & \\
\hline 4. A voz en cuello & & & & & \\
\hline 5. Blanquillo & & & & & \\
\hline 6. Blanquiar & & & & & \\
\hline 7. Bolear & & & & & \\
\hline 8. Cacareado & & & & & \\
\hline 9. Calentano & & & & & \\
\hline
\end{tabular}




\section{Bibliografia}

Ahumada Lara, I. (1989). Aspectos de lexicografía teórica. Granada: Universidad de Granada.

Alavar Ezguerra, M. (1982). Diccionario y Gramática. LEA. Lingüística Española Actual, IV, 151-212.

Alvar Ezguerra, M. (1993). Lexicografía descriptiva. Barcelona: Vox.

Fernández Sevilla, J. (1974). El vocabulario dialectal. En I. C. Cuervo, Problemas de lexicografía actual. Bogotá: Instituto Caro y Cuervo.

Flórez, L. (1981-1983). Atlas lingüístico y etnográfico de Colombia. Bogotá: Instituto Caro y Cuervo.

Garriga Escribano, C. (1999). Las marcas de uso en los diccionarios del español. Revista de Investigación Lingüística, 1, 75-110.

González, M. I. (2002-2003). Freseología y lexicografía: análisis y propuestas. Revista de Lexicografía, IX, 29-55.

Haensch, G. (1982). La lexicografía. De la lingüística teórica a la lingüística práctica. Madrid: Gredos.

Lara, L. F. (1990). Dimensiones de la lexicografía: a propósito del Diccionario del Español de México. México: El Colegio de México.

Martínez de Sousa, J. (1995). Diccionario de lexicografía práctica. Barcelona: Vox.

Medina, A. (2003). Lexicografía española. Barcelona: Ariel.

Rosenblat, Á. (1971). Nuestra lengua en ambos mundos. Navarra: Alianza. 